Forthcoming in the Journal of Monetary Economics

\title{
Term structure evidence on interest rate smoothing and monetary policy inertia \#
}

\author{
Glenn D. Rudebusch * \\ Federal Reserve Bank of San Francisco, \\ 101 Market Street, San Francisco, CA 94105, USA
}

August 2001

\begin{abstract}
Numerous studies have used quarterly data to estimate monetary policy rules or reaction functions that appear to exhibit a very slow partial adjustment of the policy interest rate. The conventional wisdom asserts that this gradual adjustment reflects a policy inertia or interest rate smoothing behavior by central banks. However, such quarterly monetary policy inertia would imply a large amount of forecastable variation in interest rates at horizons of more than three months, which is contradicted by evidence from the term structure of interest rates. The illusion of monetary policy inertia evident in the estimated policy rules likely reflects the persistent shocks that central banks face.

JEL classification: E4; E5

Keywords: Monetary policy; Term structure of interest rates; Taylor rule

\# For helpful comments, I thank many colleagues throughout the Federal Reserve System as well as participants in the 2000 CEPR Summer Institute in Amsterdam, the fall 2000 NBER Monetary Economics meeting, and seminars at Stanford, UCLA, Berkeley, UC-San Diego, UC-Riverside, ASU, the Bank of England, the Riksbank, and the BIS. Niloofar Badie, Kirran Bari, Casey Cornwell, Carolina Marquez, and Adam Yu provided excellent research assistance. The views expressed here are solely those of the author and not necessarily those of the Federal Reserve.

* Tel. + 1-415-974-3173; fax: + 1-415-974-2168

E-mail address: Glenn.Rudebusch@sf.frb.org (G.D. Rudebusch)
\end{abstract}




\section{Introduction}

How quickly do central banks adjust monetary policy in response to developments in the economy? A common view among economists is that the short-term policy interest rate in many countries is changed at a very sluggish pace over several quarters. The evidence supporting this view is found in the many monetary policy rules or reaction functions estimated in the literature with quarterly data. These policy rules take the general partial adjustment form $i_{t}=(1-\rho) i_{t}^{*}+\rho i_{t-1}$, where $i_{t}$ is the level of the policy interest rate in quarter $t$, which is set as a weighted average of the current desired level, $i_{t}^{*}$, and last quarter's actual value, $i_{t-1}$. Based on historical data, estimates of $\rho$ are often in the range of 0.8 , so these empirical rules appear to imply a very slow speed of adjustment of the policy rate to its fundamental determinants. This gradual adjustment of the policy rate over several quarters to its desired level is widely interpreted as evidence of an "interest rate smoothing" or "monetary policy inertia" behavior by central banks. For example, Clarida, Gali, and Gertler (2000, pp. 157-158) describe their U.S. estimates of various partial adjustment policy rules: ". . . the estimate of the smoothing parameter $\rho$ is high in all cases, suggesting considerable interest rate inertia: only between 10 and 30 percent of a change in the [desired interest rate] is reflected in the Funds rate within the quarter of the change. Thus, our estimates confirm the conventional wisdom that the Federal Reserve smooths adjustments in the interest rate." Some of the many other recent papers with a similar inertial interpretation of monetary policy rules include Woodford (1999), Goodhart (1999), Levin, Wieland, and Williams (1999), Amato and Laubach (1999), and Sack (1998).

Furthermore, a few researchers have also argued recently that the monetary policy inertia apparently present in the real world may be an optimal behavioral response on the part of central banks. For example, one popular such normative argument contends that the quarterly policy inertia and interest rate smoothing behavior helps the central bank focus the expectations of agents in the economy on its stabilization goals and thereby achieve a better outcome (e.g., Levin, Wieland, and Williams, 1999, Woodford, 1999, and Sack and Wieland, 2000).

There is another quite separate literature on "interest rate smoothing," which, at least superficially, may appear to be consistent with the quarterly interest rate smoothing described above. This earlier literature analyzes changes in policy interest rates on a day-by-day basis. Both in the U.S. (e.g., Goodfriend, 1991, and Rudebusch, 1995) and in Europe, Japan, and Australia (e.g., Goodhart, 1997, and Lowe and Ellis, 1997), central banks appear to follow a pattern of behavior in which changes in the policy rate are undertaken at discrete intervals and 
in discrete amounts. ${ }^{1}$ For example, Rudebusch (1995, p. 264) defines short-term (or weekly) interest rate smoothing as the Fed adjusting interest rates “. . . in limited amounts . . . over the course of several weeks with gradual increases or decreases (but not both) . . .."2

Many have assumed - including the monetary policy rule papers cited above - that such short-term interest rate smoothing implies the quarterly interest rate smoothing found in the empirical policy rules. However, the earlier short-term interest rate smoothing refers to a partial adjustment over the course of several weeks, while quarterly interest rate smoothing refers to a partial adjustment over the course of several quarters. With such disparate time frames, the two types of partial adjustment are in fact largely independent, so a central bank could conduct either type of smoothing without much of the other. Indeed, an important point in the shortterm interest rate smoothing literature is that although central banks smooth interest rates on a week-to-week or month-to-month basis, there is essentially no quarterly interest rate smoothing. This description follows Mankiw and Miron (1986, p. 225), who note that the postwar term structure of interest rates suggests that at a quarterly frequency ". . . while the Fed might change the short rate in response to new information, it always (rationally) expected to maintain the short rate at its current level." Goodfriend (1991, p. 10) provides an identical random-walk characterization of the policy rate and argues that changes in the rate set by the Fed ". . . are essentially unpredictable at forecast horizons longer than a month or two." Similarly, Rudebusch (1995, p. 264) characterizes the Fed's behavior as, “. . . beyond a horizon of about a month, there are no planned movements to react to information already known." Thus, the earlier short-term interest rate smoothing literature rejects any partial adjustment or policy inertia at

\footnotetext{
${ }^{1}$ Also, see Balduzzi, Bertola, and Foresi (1997), Dotsey and Otrok (1995), and Eijffinger, Schaling, and Verhagen (1999).

${ }^{2}$ The short-term interest rate smoothing literature distinguishes three interest rates: the market rate at which funds are actually traded, $i_{t}^{m}$; the "target" rate that the central bank enforces in the market on a week-by-week basis, $i_{t}$; and the desired rate, $i_{t}^{*}$, that the central bank would set as its target if unconstrained by a desire to adjust the target rate slowly. Note that the "target" rate is not the desired rate. Furthermore, although the market and target rates, which are the ones reported in the popular press, can differ substantially on any given day, they are largely indistinguishable on a monthly average basis as the central bank hits its target, so both are denoted as $i_{t}$ in this paper (which considers quarterly average data). As examples, Rudebusch (1995) explicitly models $i_{t}^{m}$ and $i_{t}$ on a daily basis (with $i_{t}^{*}$ implicit), while Dotsey and Otrok (1995) model $i_{t}^{*}$ and $i_{t}$ on a monthly average basis (so $i_{t}^{m}=i_{t}$ ).
} 
a quarterly frequency. ${ }^{3}$

This paper argues that quarterly interest rate smoothing (or monetary policy inertia) is a very modest phenomenon in practice, which accords with the earlier characterization of monetary policy partial adjustment as involving only a very short-term smoothing of rates. This argument, however, must account for the many estimated policy rules that appear to indicate that a high degree of quarterly interest rate smoothing is present in the real world. This seemingly straightforward descriptive evidence of slow adjustment from the inertial empirical policy rules is summarized in the next section, while Section 3 outlines the related normative arguments for the optimality of inertial behavior in a New Keynesian model of output and inflation.

Evidence against the existence of an inertial policy rule is obtained from the behavior of market interest rates at the short-term end of the yield curve. As documented in Section 4, there appears to be very little information generally available in financial markets regarding future interest rate movements beyond the next one or two months, which is consistent with the results of Mankiw and Miron (1986) and many others. In contrast, Section 5 derives the term structure implications of monetary policy inertia in a New Keynesian model and shows that the large $\rho$ in an inertial rule implies that typically there are predictable future changes in the policy rate, which under rational expectations should be embodied in the term structure. Thus, there is an inconsistency between the term structure implications of quarterly interest rate smoothing and the historical term structure evidence. Furthermore, this inconsistency is robust to a variety of different assumptions about the specification of the model and the policy rule.

Assuming financial markets process information efficiently, the term structure evidence implies that the empirical policy rules displaying substantial partial adjustment are misspecified. Section 6 argues that such partial adjustment could be spuriously attributed to a non-inertial central bank, that is, one that displays no quarterly interest rate smoothing. This argument is based on the econometric near-observational equivalence of the partial adjustment rule and a non-inertial rule with serially correlated shocks. That is, significant persistent shocks may explain the illusion of monetary policy inertia, and the conventional empirical partial adjust-

\footnotetext{
${ }^{3}$ This can be shown formally by simulating the models of short-term interest rate smoothing and fitting a partial adjustment model to the quarterly averaged simulated data. For example, data on the desired and actual funds rates $\left(i_{t}^{*}\right.$ and $i_{t}$ ) can be generated according to Eqs. (5) and (6) in Dotsey and Otrok (1995), and after quarterly averaging, the $\hat{\rho}$ in an estimated partial adjustment policy rule is only about 0.1 .
} 
ment rules are misspecified. Furthermore, when monetary policymakers respond to current information - including the persistent shock - interest rate predictability is quite low, which is consistent with the term structure evidence.

\section{The policy inertia in estimated rules}

Many recent studies have estimated models of central bank behavior. A sizable fraction of these empirical policy rules or reaction functions follow Taylor (1993), who proposed a simple rule for monetary policy that sets the quarterly average level of the short-term policy interest rate $\left(i_{t}\right)$ in response to (four-quarter) inflation $\left(\bar{\pi}_{t}\right)$ and the output gap $\left(y_{t}\right)$ :

$$
i_{t}=r^{*}+\bar{\pi}_{t}+0.5\left(\bar{\pi}_{t}-\pi^{*}\right)+0.5 y_{t},
$$

where $r^{*}$ is the equilibrium real rate and $\pi^{*}$ is the inflation target. However, for an empirical version of this rule with estimated response coefficients, a lagged policy rate is also usually included. Accordingly, a typical rule regression has the generic partial adjustment form (ignoring constants) of

$$
i_{t}=\left(1-\rho_{1}\right)\left(g_{\pi} \bar{\pi}_{t}+g_{y} y_{t}\right)+\rho_{1} i_{t-1}+\xi_{t}
$$

where $\rho_{1}, g_{\pi}$, and $g_{y}$ are the coefficients of what is denoted here as Rule 1 .

For example, a least squares regression of Rule 1 on U.S. data from 1987:Q4 to 1999:Q4 yields (ignoring constants)

$$
\begin{aligned}
& i_{t}=.27\left(1.53 \bar{\pi}_{t}+.93 y_{t}\right)+.73 i_{t-1}+\xi_{t} \text {, } \\
& \sigma_{\xi}=.36, \quad \bar{R}^{2}=.96,
\end{aligned}
$$

where the interest rate is the quarterly average federal funds rate. ${ }^{4}$ In this regression, the estimated values of the response coefficients - namely, $g_{\pi}=1.53$ for the inflation response and $g_{y}=0.93$ for the output response - are just above the 1.5 and 0.5 that Taylor (1993) originally proposed. Similar estimates are obtained in other empirical studies. ${ }^{5}$ Most notable, however,

\footnotetext{
${ }^{4}$ Inflation is defined using the GDP chain-weighted price index (denoted $P_{t}$, so $\pi_{t}=400\left(\ln P_{t}-\ln P_{t-1}\right)$ and $\left.\bar{\pi}_{t}=\frac{1}{4} \Sigma_{j=0}^{3} \pi_{t-j}\right)$, and the output gap is defined as the percent difference between actual real GDP $\left(Q_{t}\right)$ and potential output $\left(Q_{t}^{*}\right)$ estimated by the Congressional Budget Office (i.e., $\left.y_{t}=100\left(Q_{t}-Q_{t}^{*}\right) / Q_{t}^{*}\right)$.

${ }^{5}$ See, for example, Kozicki (1999), Amato and Laubach (1999), Sack (1998), and Judd and Rudebusch (1998).
} 
is the large and highly significant estimates of the coefficient on the lagged policy rate, the $\hat{\rho}_{1}=0.73$. Indeed, such significant lagged dependence in the empirical estimation of Rule 1 is an extremely robust result in the literature. For example, across six different quarterly U.S. data samples (differing in output gap definitions), Kozicki (1999) reports a range of $\hat{\rho}_{1}$ from 0.75 to 0.82, while across 16 different quarterly samples of U.S. data (differing in output gap, inflation, and sample period definitions), Amato and Laubach (1999) report a range of $\hat{\rho}_{1}$ from 0.78 to 0.92 .

In contrast to Eq. (3), the regression of the non-inertial form of Rule 1, which imposes the constraint that $\rho_{1}=0$, yields

$$
\begin{gathered}
i_{t}=\underset{(.13)}{1.59 \bar{\pi}_{t}}+\underset{(.09)}{.68} y_{t}+\xi_{t}, \\
\sigma_{\xi}=.73, \quad \bar{R}^{2}=.84, \quad D W=.33
\end{gathered}
$$

which has a significantly worse fit and severely serially correlated errors, although the estimates of $g_{\pi}$ and $g_{y}$ are not very different. ${ }^{6}$

The evidence for significant lagged dependence is also robust across different variations of the Taylor rule. In particular, Clarida, Gali, and Gertler (2000) recommend a forecast-based specification of the Taylor rule, which I denote as Rule 2,

$$
i_{t}=\left(1-\rho_{2}\right)\left(g_{\pi} E_{t-1} \bar{\pi}_{t+4}+g_{y} E_{t-1} y_{t}\right)+\rho_{2} i_{t-1}+\xi_{t}
$$

where $E_{t-1} \bar{\pi}_{t+4}$ is the forecast of annual inflation five quarters ahead based on the $t-1$ information set and $E_{t-1} y_{t}$ is the forecast of the time $t$ output gap based on the $t-1$ information set. An instrumental variables estimate of Rule 2 over the 1987-99 sample is ${ }^{7}$

$$
\begin{aligned}
& i_{t}=.21\left(1.40 E_{t-1} \bar{\pi}_{t+4}+.90 E_{t-1} y_{t}\right)+.79 i_{t-1}+\xi_{t} \text {, } \\
& \text { (.50) } \\
& \sigma_{\xi}=.41, \quad \bar{R}^{2}=.95 \text {. }
\end{aligned}
$$

These parameter estimates are broadly similar to ones for this specification given in Clarida, Gali, and Gertler (2000, Table 5), although they report even slower partial adjustment with a

\footnotetext{
${ }^{6}$ In all the regressions in this section, robust standard errors for the coefficients are reported in parentheses. For example, there is some residual serial correlation in Eq. (3) as well, but for simplicity this paper just considers first order autoregressive terms.

${ }^{7}$ Four lags of inflation, the output gap, and the interest rate are used as instruments.
} 
$\hat{\rho}_{2}=0.91$. As above, there is a significant contrast in fit with the estimated non-inertial Rule 2, which has the restriction that $\rho_{2}=0$, although again the sizes of the $\hat{g}_{\pi}$ and $\hat{g}_{y}$ are similar,

$$
\begin{aligned}
& i_{t}=1.33 E_{t-1} \bar{\pi}_{t+4}+.59 E_{t-1} y_{t}+\xi_{t}, \\
& \text { (.32) } \\
& \sigma_{\xi}=1.09, \quad \bar{R}^{2}=.65, \quad D W=.35
\end{aligned}
$$

In short, as many have noted, the partial adjustment forms of Rules 1 and 2 appear to fit the data significantly better than those without partial adjustment. This significant lagged dependence in empirical Taylor-type rules also appears to be a quite general feature found in a variety of countries in Europe and elsewhere. For example, Clarida, Gali, and Gertler (1998) estimate Rule 2 on quarterly European data and obtain estimates of $\rho_{2}$ above 0.90 in Germany, France, Italy, and the UK, and Nelson (2000) provides estimates of Rule 1 for the UK that also display significant lagged dependence.

Along with the uniform results on the size and significance of the lagged policy interest rate in the empirical rules, there is also a standard partial adjustment interpretation of this term. When $\rho_{1}$ or $\rho_{2}$ equals zero, the current policy rate is based solely on current macroeconomic performance (actual or expected). When these lag coefficients are positive (but less than one), then the current policy rate is set equal to a weighted average of this current desired interest rate and last quarter's rate. This conventional wisdom of quarterly monetary policy partial adjustment has been advanced by numerous authors, including Goodhart (1999), Levin, Wieland, and Williams (1999), Woodford (1999), Amato and Laubach (1999), Clarida, Gali, and Gertler (2000), and Sack and Wieland (2000). Such partial adjustment behavior is typically termed "interest rate smoothing" because the resulting interest rate series will be less volatile than would be suggested by the determinants of policy. Indeed, the degree of quarterly interest rate smoothing or inertia is often measured by the size of the speed of adjustment coefficient because as $\rho_{1}$ or $\rho_{2}$ increases for a given policy rule, the standard deviation of $\Delta i_{t}$ falls. ${ }^{8}$

Given the simple forms of Rules 1 and 2, it may seem that the significant estimated partial adjustment could reflect a misspecified reaction function. One such misspecification might

\footnotetext{
${ }^{8}$ This is true for a single stochastic equation but is, of course, not necessarily true in the context of a complete model. For example, in the Rudebusch and Svensson (1999) model, increasing $\rho_{1}$ can increase the variance of $\Delta i_{t}$ and even lead to dynamic instability. Also, a rule with a larger autoregressive coefficient than another rule does not necessarily produce smoother interest rates, because the policy rate volatility also depends on the volatility of the other arguments of the rules.
} 
involve structural shifts in the parameters of the policy rule for different policy regimes, which might account for the significant lagged interest rate even if the central bank was non-inertial; however, Clarida, Gali, and Gertler (2000) and others provide rule estimates over numerous subsamples, and all display a large partial adjustment lag coefficient. Alternatively, Rules 1 and 2 may be misspecified because of the omission of a persistent, serially correlated variable that influences monetary policy. Such an omitted variable could also produce the spurious appearance of partial adjustment in the estimated rule. However, in a wide variety of less parsimonious specifications of $i_{t}^{*}$, significant estimates of $\rho$ are still obtained. For example, McNees (1992), McCallum and Nelson (1999), and Fair (2000) estimate more complicated structural monetary policy rules and obtain significant evidence of policy inertia with partial adjustment coefficients on the order of 0.8 or higher. In addition, numerous monetary VAR estimates, which provide a very popular implementation of an empirical policy reaction function, also show significant inertia. The estimated VAR interest rate equations contain large and significant lagged interest rate coefficients despite including a wide variety of other regressors. For example, Rudebusch (1998, Table 2) reports the sum of the lagged funds rate coefficients in the reduced form of a well-known quarterly VAR interest rate equation (which has 24 non-interest-rate regressors) as $0.95 .^{9}$

Still, this paper takes issue with the "conventional wisdom" that quarterly monetary policy inertia exists and argues that the common empirical monetary policy rules are indeed misspecified. However, as described below, this misspecification appears difficult to detect directly; thus, this paper focuses on indirect term structure evidence of the misspecification. As a first step, the next section introduces a model of the economy and considers the optimality of policy inertia.

\section{Optimal monetary policy inertia}

The above empirical policy rules imply a very slow speed of adjustment. A $\hat{\rho}_{1}$ or $\hat{\rho}_{2}$ of 0.8 implies a 20 percent adjustment each quarter, so in a year, a central bank would complete only 60 basis points of a desired one percentage point change. Still, such sluggish behavior may be optimal for a central bank. An obvious explanation is that $i_{t-1}$ is likely an important state variable, so the fully optimal instrument rule would include a response to its value (e.g., Rudebusch

\footnotetext{
${ }^{9}$ Rudebusch (1998) and Goodfriend (2000) criticize the monetary policy partial adjustment in recent VARs as implausible.
} 
and Svensson, 1999). ${ }^{10}$ An important example of this occurs in an explicitly forward-looking model, where partial adjustment can be optimal if the private sector is forward-looking and the monetary policymaker is credibly committed to a gradual policy rule (see Woodford, 1999, Rotemberg and Woodford, 1999, Levin, Wieland, and Williams, 1999, Sack and Wieland, 2000, and Amato and Laubach, 1999). In such a situation, the small inertial changes in the policy interest rate that are expected in the future can have a large effect on current supply and demand and can help the central bank control macroeconomic fluctuations. ${ }^{11}$

This argument can be elucidated within an empirical New Keynesian model. The key aggregate relationships of the simple theoretical version of this model are

$$
\begin{gathered}
\pi_{t}=\mu_{\pi} E_{t} \pi_{t+1}+\left(1-\mu_{\pi}\right) \pi_{t-1}+\alpha_{y} y_{t}+\varepsilon_{t}, \\
y_{t}=\mu_{y} E_{t} y_{t+1}+\left(1-\mu_{y}\right) y_{t-1}-\beta_{r}\left(i_{t}-E_{t} \pi_{t+1}-r^{*}\right)+\eta_{t},
\end{gathered}
$$

where $E_{t} \pi_{t+1}$ and $E_{t} y_{t+1}$ are the expectations of period $t+1$ inflation and output conditional on a time $t$ information set. Much of the appeal of this model lies in its foundations in a dynamic general equilibrium model with nominal price rigidities. ${ }^{12}$ An empirical version of this model suitable for quarterly data, where longer leads and lags appear appropriate given the institutional length of contracts and delays in information flows and processing, reformulates Eq. (8) and (9) as

$$
\begin{gathered}
\pi_{t}=\mu_{\pi} E_{t-1} \bar{\pi}_{t+3}+\left(1-\mu_{\pi}\right) \Sigma_{j=1}^{4} \alpha_{\pi j} \pi_{t-j}+\alpha_{y} y_{t-1}+\varepsilon_{t}, \\
y_{t}=\mu_{y} E_{t-1} y_{t+1}+\left(1-\mu_{y}\right) \Sigma_{j=1}^{2} \beta_{y j} y_{t-j}-\beta_{r}\left(r_{t-1}-r^{*}\right)+\eta_{t},
\end{gathered}
$$

where $E_{t-1} \bar{\pi}_{t+3}$ represents the expectation of average inflation over the next year and $r_{t-1}$ is the real rate relevant for output. In particular, $r_{t-1}$ is defined as a weighted combination of an

\footnotetext{
${ }^{10}$ As noted by Levin, Wieland, and Williams (1999), this may be especially true for restricted rules, such as Rules 1 and 2, because the lagged policy rate may proxy for excluded lags of other variables.

${ }^{11}$ As a second reason why partial adjustment may be optimal, Sack (2000), Sack and Wieland (2000), and Söderström (2000) cite multiplicative parameter uncertainty; however, the results of Rudebusch (2001) and Peersman and Smets (1999) indicate that the effect of such uncertainty is quite modest empirically.

${ }^{12}$ For explicit derivations and discussion, see Woodford (1996), Goodfriend and King (1997), Walsh (1998), Clarida, Gali, and Gertler (1999), Svensson (1999a, b), McCallum and Nelson (1999), and Rudebusch (2002).
} 
ex ante 1-year rate and an ex post 1-year rate:

$$
r_{t-1}=\mu_{r}\left(E_{t-1} \bar{t}_{t+3}-E_{t-1} \bar{\pi}_{t+4}\right)+\left(1-\mu_{r}\right)\left(\bar{\imath}_{t-1}-\bar{\pi}_{t-1}\right),
$$

where $\bar{\imath}_{t}$ is a four-quarter average of past interest rates, i.e., $\bar{\imath}_{t}=\frac{1}{4} \Sigma_{j=0}^{3} i_{t-j}$.

This model allows the analysis below to consider a wide range of explicit forward-looking behavior, which is important given the uncertainty about the quantitative importance of expectations. As a theoretical matter, the values of $\mu_{\pi}, \mu_{y}$, and $\mu_{r}$ are not clearly determined..$^{13}$ Furthermore, the empirical evidence on the appropriate values of these parameters, which is surveyed in Rudebusch (2002), is not decisive. At one extreme, the model with $\mu_{\pi}$, $\mu_{y}$, and $\mu_{r}$ set equal to zero matches the completely adaptive expectations model of Rudebusch and Svensson (1999) and Rudebusch (2001), which has had some success in approximating the time series data in the manner of a small estimated VAR (see Fuhrer, 1997, and Estrella and Fuhrer, 1998). In this extreme model, inflation and output are not based on explicit expectations but are based completely on lags (which may implicitly represent adaptive expectations), and the real rate is an average of the past four quarters of real rates (which may represent planning and production lags from interest rates to output or an adaptive expectations version of the term structure as in Modigliani and Schiller, 1973). However, estimated forward-looking models also have had some success in fitting the data, as in Rotemberg and Woodford (1999), Fuhrer (2000), McCallum and Nelson (1999), and Fuhrer and Moore (1995). The analysis below takes a very eclectic view and conditions on a wide range of possible values for $\mu_{\pi}, \mu_{y}$, and $\mu_{r}$. In contrast, there is less contention regarding the values of the other parameters in the model, and these are set equal to the values given in Table 1, which are obtained from the data in Rudebusch (2002) for a very similar model. ${ }^{14}$

In order to calculate optimal monetary policy, I assume a standard loss function in which the central bank minimizes variation in inflation around its target $\pi^{*}$, the output gap, and changes

\footnotetext{
${ }^{13}$ From well-known contracting models of price-setting behavior it is possible to derive an inflation equation with $\mu_{\pi} \approx 1$ (e.g., Roberts, 1995). However, many authors assume that with realistic costs of adjustment and overlapping price and wage contracts there will be some inertia in inflation, so $\mu_{\pi}$ will be less than one, and with even higher costs for adjusting output, $\mu_{y}$ is likely much less than one as well. See Svensson (1999a, b) and Fuhrer and Moore (1995) and Fuhrer (1997).

${ }^{14}$ These are also little different from the values given in Rudebusch and Svensson (1999); in any case, the qualitative results below are robust to their variation. The estimated constants are not reported.
} 
in the interest rate (see Rudebusch and Svensson, 1999, and Clarida, Gali, and Gertler, 1999):

$$
\mathrm{E}\left[L_{t}\right]=\operatorname{Var}\left[\bar{\pi}_{t}-\pi^{*}\right]+\lambda \operatorname{Var}\left[y_{t}\right]+\nu \operatorname{Var}\left[\Delta i_{t}\right]
$$

where $\Delta i_{t}=i_{t}-i_{t-1}$, and the parameters $\lambda \geq 0$ and $\nu \geq 0$ are the relative weights on output and interest rate stabilization, respectively, with respect to inflation stabilization. (Note this loss function is only used in this section for the discussion of optimal inertia.)

Table 2 summarizes the optimal amount of monetary policy inertia for various models, rules, and loss functions. The table displays the lag coefficients $\rho_{1}$ and $\rho_{2}$ from the optimal versions of Rules 1 and 2, across models with a range of forward-looking behavior. In particular, for inflation, $\mu_{\pi}$ is set equal to $0.1,0.3$, or 0.5 because the many available empirical estimates described in Rudebusch (2002) suggest that a very broad plausible range for $\mu_{\pi}$ is between 0 and 0.6. ${ }^{15}$ Similarly for output, $\mu_{y}$ is set equal to either 0 or 0.3 . Almost all empirical estimates have assumed that $\mu_{y}=0$ (e.g., Fuhrer and Moore 1995); however, Fuhrer (2000) estimates a habit persistence model, which suggests that $\mu_{y}$ is approximately equal to 0.3 (see Rudebusch, 2002). Finally for interest rates, $\mu_{r}$ is varied over essentially the entire range, so $\mu_{r}=0.1$, 0.5 , or 0.9 , because the multicollinearity of many interest rates makes it hard to obtain decisive empirical evidence on its value (e.g., Fuhrer and Moore, 1995). The coefficients of Rules 1 and 2 are optimized in various models according to two different parameterizations of the loss function. Columns 4 and 5 of Table 2 provide the optimal $\rho_{1}$ and $\rho_{2}$ with $\lambda=1$ and $\nu=0.5$, the baseline case in Rudebusch and Svensson (1999), while columns 6 and 7 provide the optimal $\rho_{1}$ and $\rho_{2}$ with $\lambda=1$ and $\nu=0.1$, which incorporates a very modest incentive to reduce interest rate volatility. ${ }^{16}$ With $\nu$ equal to 0.5 or 0.1 , respectively, these loss functions equally penalize a 1 percent output gap, a 1 percentage point inflation gap, and a 1.41 or a 3.16 percentage point quarterly change in the funds rate. This appears to be a plausible range of penalty on interest rate volatility given the various reasons to reduce such volatility that have been proposed in the literature. ${ }^{17}$

\footnotetext{
${ }^{15}$ For example, Fuhrer (1997) estimates $\mu_{\pi}$ to be about zero, while Fuhrer and Moore (1995) assumes $\mu_{\pi}$ is 0.5 .

${ }^{16}$ The results in Table 2 are obtained by numerically minimizing the loss function over the parameters $g_{\pi}, g_{y}$, and $\rho_{j}$ in the model of (3.1), (3.1), and Rule $j$. The policy rule is subject to an i.i.d. error with $\sigma_{\xi}=0.4$, which is in the range of the empirical estimates in Section 2. As usual, the policy rule is assumed to be perfectly credible, so agents know the rule and assume (correctly) that it will be followed. The results are obtained using the "AIM" algorithm (Anderson and Moore, 1985) available at http://www.federalreserve.gov/pubs/oss/oss4/aimindex.html.

${ }^{17}$ There are three broad such motives (e.g., Lowe and Ellis, 1997). First, interest rate volatility may induce
} 
As is evident in Table 2, a large range of optimal lag coefficients - between 0 and 0.8 - can be rationalized for some combination of model and loss function. Surprisingly, there is little dependence of the optimal $\rho_{1}$ or $\rho_{2}$ on the values of $\mu_{\pi}$ or $\mu_{y}$. Instead, the degree of optimal quarterly interest rate smoothing is crucially dependent on the value of $\mu_{r}$, which determines the degree to which interest rate expectations are forward-looking. This is consistent with the interpretation of Woodford (1999) and Levin, Wieland, and Williams (1999) that policy inertia is optimal when it alters expectations of future interest rates that are also important determinants of current demand.

\section{Term structure evidence on interest rate predictability}

The preceding two sections documented the large and significant estimated coefficient on the lagged interest rate in quarterly central bank reaction functions as well as the optimality of such monetary policy partial adjustment or inertia when economic agents are forward-looking with respect to future interest rate movements. This section focuses on measuring how much financial market participants actually know about future interest rate movements. This evidence will provide some crucial benchmarks for the next section, which quantifies the term structure implications of monetary policy inertia.

The partial adjustment of monetary policy by a central bank suggests that there are forecastable future movements in the policy interest rate. The amount of such forecastable variation can be measured with a standard term structure regression such as:

$$
i_{t+j}-i_{t+j-1}=\delta+\gamma\left(E_{t} i_{t+j}-E_{t} i_{t+j-1}\right)+\psi_{t+j}^{j},
$$

(for $j \geq 1$ ). This equation regresses the realized change in the policy rate between two adjacent quarters on the expected such change. ${ }^{18}$ Under rational expectations, $i_{t+j}=E_{t} i_{t+j}+e_{t+j}$, where $e_{t+j}$, the expectational error, has a mean of zero and is uncorrelated with time t information. In instability in financial markets (e.g., Goodfriend, 1991, Rudebusch, 1995, Cukierman, 1996). Second, large interest rate changes may be difficult to achieve politically because of the decision-making process (e.g., Goodhart, 1997) or because such changes may be taken as an adverse signal of inconsistency and incompetence (e.g., Goodhart, 1999). Finally, smaller interest rate changes seem to make it less likely that the zero bound on nominal interest rates would be reached (though Woodford, 1999, disagrees).

\footnotetext{
${ }^{18}$ These "marginal" regressions are common in the literature (e.g., Mishkin, 1988); however, I obtained similar results with other forms as well.
} 
this case, the interest rate forecasting regression Eq. (14) would yield in the limit an estimate of $\hat{\delta}=0$ and $\hat{\gamma}=1$. Furthermore, for assessing monetary policy inertia, a statistic of particular interest is the $R^{2}$ of this regression, which provides a measure of the forecastability of future interest rate changes (for discussion of such measures, see Diebold and Kilian, 2001).

Many papers have estimated term structure regressions such as Eq. (14) for the postwar period using 3- and 6-month or 6- and 12-month Treasury bill spreads as proxies for expectations (see, for example, Mankiw and Miron, 1986, Mishkin, 1988, Cook and Hahn, 1990, and Rudebusch, 1995). These studies typically have obtained $R^{2}$ 's very close to zero. For example, in a 1959-1979 sample, Mankiw and Miron (1986, Table 1) obtain an $R^{2}$ of 0.02 in a regression of the change in the 3-month rate on the 3 - and 6-month spread. However, these results may be too pessimistic because they typically cover a long sample that is unlikely to be a consistent monetary policy regime (see Fuhrer, 1996). In contrast, the term structure implications derived in the next section assume that agents know the policy rule that the central bank is committed to. As a complement to the earlier results, I estimate Eq. (14) with rates on 3-month eurodollar and eurodollar futures, which have been the trading vehicle of choice for hedging short-run future interest rate movements since the mid-1980s. ${ }^{19}$ The eurodollar regressions use a short sample from 1988:01 to 2000:01, covering what is arguably a single consistent policy regime.

Denote $E D(t+j)_{t}$ as the interest rate on eurodollar deposits during quarter $t+j$ that is expected at the end of quarter $t$. Thus, $E D(t+1)_{t}$ is the spot 3 -month eurodollar rate at the end of quarter $t$, and $E D(t+2)_{t}$ is the rate on a eurodollar futures contract that settles 3 months ahead. ${ }^{20}$ Then assume that $E D(t+j)_{t}=E_{t} i_{t+j}+\phi_{t}^{j}$, where $\phi_{t}^{j}$ is the term premium associated with the $j$ th contract. Under the expectations hypothesis of the term structure, the term premia are assumed to be constant over time, but in practice it is widely recognized that there is some time variation. The consequences of time-varying term premia are discussed below.

Using eurodollar data to predict the one-quarter-ahead change in the quarterly average funds rate from 1988:Q1 to 2000:Q1, equation Eq. (14) with $j=1$ is estimated as

$$
i_{t+1}-i_{t}=\underset{(.05)}{-.25}+\underset{(.10)}{.83\left(E D(t+1)_{t}-i_{t}\right)}+\psi_{t+1}^{1},
$$

\footnotetext{
${ }^{19}$ Eurodollar futures contracts are based on the 90-day London Interbank Offered Rate (LIBOR). For further details, see Jegadeesh and Pennacchi (1996).

${ }^{20}$ For the three regressions using eurodollar rates, quarters are defined to start at the eurodollar futures contract settlement dates (which occur about two weeks before the start dates of the usual quarters) in order to capture true two- and three-quarter-ahead expectations.
} 


$$
\sigma_{\psi 1}=.30, \quad R^{2}=.57
$$

This equation indicates that the 3 -month eurodollar rate forecasts $\Delta i_{t+1}$ quite well (with an average term premium of about 25 basis points). The $R^{2}$ indicates that over 50 percent of the one-quarter-ahead variation in the funds rate is known by the end of the preceding quarter. This predictability is consistent with the evidence and interpretation in Rudebusch (1995) of interest rate smoothing at a weekly and monthly frequency. That is, at the end of quarter $t$, financial markets have some information about changes during the first several weeks of the following quarter. ${ }^{21}$ In addition, in this regression, changes in the funds rate during quarter $t$ (which are of course known at the end of quarter $t$ ) will also help predict the quarterly average change $\Delta i_{t+1}$. Still, after replacing $i_{t}$ with the end of quarter $t$ funds rate, substantial predictive power remains with $R^{2} \approx .3$.

Of particular interest in assessing quarterly monetary policy inertia will be the predictive ability at slightly longer horizons. Predicting the one-quarter change in the funds rate two quarters ahead (Eq. (14) with $j=2$ ) yields ${ }^{22}$

$$
\begin{gathered}
i_{t+2}-i_{t+1}=\underset{(.07)}{-.04}+\underset{(.18)}{.45\left(E D(t+2)_{t}-E D(t+1)_{t}\right)+\psi_{t+2}^{2}} \\
\sigma_{\psi 2}=.42, \quad R^{2}=.11
\end{gathered}
$$

Predicting $\Delta i_{t+3}$ at quarter $t$ yields

$$
\begin{gathered}
i_{t+3}-i_{t+2}=\underset{(.08)}{-.06}+\underset{. .30)}{.35\left(E D(t+3)_{t}-E D(t+2)_{t}\right)+\psi_{t+3}^{3}} \\
\sigma_{\psi 3}=.44, \quad R^{2}=.03
\end{gathered}
$$

These regressions indicate that there is little if any information usually available in financial markets for predicting the level of the funds rate three to six months out $\left(R^{2}=.11\right)$ and no information for predicting it six to nine months out $\left(R^{2}=.03\right) .{ }^{23}$ These $R^{2}$ 's will be used as

\footnotetext{
${ }^{21}$ In particular, this significant predictive ability for $\Delta i_{t+1}$ is consistent with the documented ability of a twomonth and one-month interest rate spread to predict the one-month-ahead change.

${ }^{22}$ For $j>1$, the forecast errors will have an $M A(j-1)$ moving average correlation, so robust standard errors are reported in parentheses.

${ }^{23}$ For predicting $\Delta i_{t+2}$, the $p$-value for the hypothesis that $R^{2}=0$ is 0.01 , and for predicting $\Delta i_{t+3}$, the $p$-value is 0.15 .
} 
benchmarks for assessing the plausibility of monetary policy inertia in the next section. These results turn out to be only marginally better than the standard ones described above. ${ }^{24}$ The lack of information in these regressions is also consistent with the evidence in Kuttner (2001), where a surprise change in the policy rate target on a particular day shifts the level of the term structure by a similar amount across all horizons, but carries little information about future changes in rates.

Finally, the presence of time-varying term premia should be considered, which, as stressed by Mankiw and Miron (1986), can have important consequences for empirical regressions like Eq. (16). The sample estimates of the $\gamma$ and $R^{2}$ of this regression will depend positively on the covariance between the independent and dependent variables, $\Delta i_{t+2}$ and $E D(t+2)_{t}-E D(t+$ $1)_{t}$, and inversely on their variances. Accordingly, as the time variation in the term premia becomes more significant (boosting the independent, noisy variation in the eurodollar spread), the estimates $\gamma$ and $R^{2}$ can be driven away from 1 even in the limit. The standard deviation of the residual to the term structure regression provides a rough upper bound on the size of the term premium. For example, in Eq. (16), $\psi_{t}^{2}=\phi_{t}^{1}-\phi_{t}^{2}+e_{t+2}-e_{t+1}$, which is a combination of term premia and the expectational errors. The expectational errors are orthogonal to the term premia; thus, the standard deviation of the term premium associated with the $t+2$ and $t+1$ eurodollar spread (i.e., $\phi_{t}^{1}-\phi_{t}^{2}$ ) is smaller than 0.42 , the standard deviation of the regression $\left(\sigma_{\psi 2}\right)$.

\section{Term structure implications of policy inertia}

The previous section provided evidence that beyond a horizon of three months there is little predictive information in financial markets about the future path of short-term interest rates. This section explores whether that evidence can be reconciled with a significant degree of quarterly monetary policy inertia. Intuitively, such a reconciliation seems unlikely, for if the funds rate is typically adjusted by only 20 percent toward its desired target in a given quarter, then the remaining 80 percent adjustment should be expected to occur in future quarters. The partial adjustment of the short-term policy interest rate embodied in Rule 1 or 2 with high $\rho_{1}$ or $\rho_{2}$ implies that there typically is a large amount of predictable future variation in the policy rate.

\footnotetext{
${ }^{24}$ This slightly better performance may be a spurious small-sample result, perhaps reflecting the unusual 1994 episode discussed below. Also, see Lange, Sack, and Whitesell (2001).
} 
Indeed, this is the essence of optimal policy inertia: Because private agents know that the policy rate is likely to be adjusted by a certain amount in the future, they change their behavior today.

The relationship between the forecastable variation in the interest rate, as measured by the $R^{2}$ of the $\Delta i_{t+2}$ prediction equation, and quarterly policy inertia, as measured by the $\rho_{1}$ and $\rho_{2}$ in Rules 1 and 2, is illustrated in Figure 1. This figure graphs the (analytical population) value of the $R^{2}$ of the regression Eq. (14), with $j=2$, as a function of the value of $\rho_{1}$ or $\rho_{2}$ for a representative case of the model described above, namely, with $\mu_{\pi}=.3, \mu_{r}=.5$, and $\mu_{y}=0$ (and the other parameters given in Table 1). ${ }^{25}$ Also, for both policy Rules 1 and 2 (Eqs. 2 and 5), $g_{\pi}$ and $g_{y}$ are set equal to 1.5 and 0.8 , respectively, and the rule error is i.i.d. with $\sigma_{\xi}=0.4$. (This calibration is in the range of the empirical rule estimates given in Section 2.) Note that even for the non-inertial policy rules there is some predictable future movement in interest rates (with $R^{2}=.10$ when $\rho_{1}=0$ and $R^{2}=.03$ when $\rho_{2}=0$ ). For example, the forecasting power with Rule 1 when $\rho_{1}=0$ reflects the fact that there are predictable changes two quarters ahead in the output gap and in the four-quarter inflation rate, which partly determine future changes in interest rates. Even though the output gap and inflation are highly persistent in levels, the associated slow mean reversion implies only a modest predictability of future quarterly changes in these series and in $\Delta i_{t}^{*}$. Most importantly, as $\rho_{1}$ and $\rho_{2}$ increase, the amount of predictable variation in $\Delta i_{t+2}$ also increases, with $R^{2}$ values of .45 at $\rho_{1}=0.8$ and .44 at $\rho_{2}=0.8 .^{26}$

This basic relationship between predictable interest rate variation and monetary inertia is robust across a wide variety of models and rules. Table 3 examines the same 18 different parameterizations of the model considered in Section 3 and non-inertial $\left(\rho_{1}=\rho_{2}=0\right)$ and inertial $\left(\rho_{1}=\rho_{2}=0.8\right)$ versions of both Rules 1 and 2. (Again, $g_{\pi}=1.5, g_{y}=0.8$, and $\sigma_{\xi}=0.4$.) In addition, a time-varying term premium, $\phi_{t}^{1}-\phi_{t}^{2}$, is included, which is assumed to be i.i.d. with a standard deviation of $0.10 .{ }^{27}$ As noted above, such a term premium reduces

\footnotetext{
${ }^{25}$ As above for Table 2 , the unique stationary rational expectations solution for each specified policy rule and model is solved via AIM (see Levin, Wieland, and Williams, 1999, and Anderson and Moore, 1985). The reducedform representation of the saddle-point solution is computed, the unconditional variance-covariance matrix of the model variables and the term spreads is obtained analytically, and the term structure regression asymptotic $R^{2}$ is calculated using the appropriate variances and covariances.

${ }^{26}$ The exception to note is that as $\rho_{1}$ or $\rho_{2}$ approach one, $i_{t}$ becomes a random walk and the model is dynamically unstable. However, if Eqs. (2) and (5) were re-written without the $\left(1-\rho_{i}\right)$ factors, then with $\rho_{1}$ or $\rho_{2}$ equal to one, $\Delta i_{t}$ would take on the persistence properties of the rule arguments.

${ }^{27}$ Mankiw and Miron (1986, Table 3) estimate the standard error of this term premium to be 0.16 , while in a more complicated time series specification with monthly data, Dotsey and Otrok (1995) estimate it to be
} 
the $R^{2}$ values. Each model and rule combination reports $R_{L}^{2}$ and $R_{U}^{2}$, which are the 5 percent lower and upper critical values, respectively, for the small-sample distribution of the $R^{2}$ (which are appropriate for 95 percent one-sided or 90 percent two-sided tests). These critical values are calculated from 5,000 simulated samples of the model and the given rule (with 100 observations each), and they allow a probabilistic assessment of the historical term structure regression results given in Section 4. The bottom line in the table gives the median $R_{L}^{2}$ and $R_{U}^{2}$ values across all models. Given the uncertainty in choosing a single model documented above, I focus on these median values (also although there is interesting variation across models, the value of $\rho_{1}$ or $\rho_{2}$ is the key determinant of interest rate predictability). Based on the historical results with eurodollar data, the benchmark $R^{2}$ value for the $\Delta i_{t+2}$ prediction regression is 0.11 . This value is included in the confidence intervals for the non-inertial $\rho_{1}=0$ and $\rho_{2}=0$ cases; indeed, it is quite close to the small-sample means (which are not shown). In contrast, for the inertial policy rules, the median $R^{2}$ confidence intervals with $\rho_{1}=.8$ and with $\rho_{2}=.8$ both lie above the historical $R^{2}$ value.

As shown in Table 4, very similar results are obtained for the $\Delta i_{t+3}$ prediction regression. Again, a $R_{L}^{2}$ and $R_{U}^{2}$ pair is calculated for each of the model and rule combinations used in Table 3. From the previous section, the benchmark value of $R^{2}$ from the historical data is 0.03 . As before, this historical value is contained in the median confidence intervals of the non-inertial policy rules but not in the median inertial policy rule intervals.

In brief, quarterly partial adjustment and interest rate smoothing or inertia do not appear to be consistent with the lack of information in the term structure of interest rates about the future path of interest rates.

\section{The illusion of monetary policy inertia}

The large estimated lag coefficients in the empirical partial adjustment policy rules appear to provide strong evidence of monetary policy inertia. However, such quarterly inertia is inconsistent with the very low interest rate forecastability in the term structure of interest rates. This section shows how the partial adjustment evidence in the empirical rules may be explained by a rationale other than policy inertia.

0.13. This standard deviation is about one-fourth the size of the regression standard error of Eq. (15), which includes the eurodollar term premia and the orthogonal expectational error. The term premia also reduce the slope estimates in the term structure regression to close to the historical values. 
As a first step, note that there is a large literature that argues that partial adjustment models such as Rules 1 and 2 are difficult to identify and estimate empirically in the presence of serially correlated shocks (e.g., Griliches, 1967, Blinder, 1986, Hall and Rosanna, 1991, and McManus, Nankervis, and Savin, 1994). In particular, a standard policy rule with slow partial adjustment and no serial correlation in the errors will be difficult to distinguish empirically from a policy rule that has immediate policy adjustment but highly serially correlated shocks. Using the 1987-1999 data sample from Section 2, this latter form of Rule 1 is estimated as ${ }^{28}$

$$
\begin{gathered}
i_{t}=\underset{(.24)}{1.24 \bar{\pi}_{t}}+\underset{(.10)}{.33 y_{t}}+\xi_{t}, \quad \xi_{t}=\underset{(.06)}{.92 \xi_{t-1}}+\omega_{t}, \\
\sigma_{\omega}=.36, \quad \bar{R}^{2}=.96 .
\end{gathered}
$$

This rule assumes immediate adjustment $\left(\rho_{1}=0\right)$ but allows for first order serial correlation of the shocks with an $\operatorname{AR}(1)$ coefficient denoted $\rho_{1}^{e}=0.92$. The corresponding estimated serially correlated shock version of Rule 2 is

$$
\begin{aligned}
& i_{t}=\underset{(.66)}{2.00 E_{t-1} \bar{\pi}_{t+4}}+\underset{(.24)}{.39 E_{t-1} y_{t}}+\xi_{t}, \quad \xi_{t}=\underset{(.11)}{.77 \xi_{t-1}}+\omega_{t} \\
& \sigma_{\omega}=.68, \quad \bar{R}^{2}=.87,
\end{aligned}
$$

with $\rho_{2}^{e}=0.77$. These two estimated autocorrelated shock versions of Rules 1 and 2 display a fit to the data as well as estimates of $g_{\pi}$ and $g_{y}$ that are broadly comparable to the partial adjustment forms in Eqs. (3) and (6).

For a more rigorous comparison, the partial adjustment and serially correlated shocks rules can be nested in a single equation and tested directly (as in Hendry and Mizon, 1978). For Rule 1 , this general nesting form is

$$
i_{t}=\rho_{1}^{a} i_{t-1}+g_{\pi} \bar{\pi}_{t}+g_{y} y_{t}-\rho_{1}^{b}\left(g_{\pi} \bar{\pi}_{t-1}+g_{y} y_{t-1}\right)+\omega_{t}
$$

The hypothesis that policy Rule 1 is non-inertial but has serially correlated shocks is $\mathrm{H} 1_{S C}$ : $\rho_{1}^{a}=\rho_{1}^{b} \equiv \rho_{1}^{e}$. With this "common factor" restriction, Eq. (20) is the quasi-differenced form that matches the $\mathrm{AR}(1)$ shock rule, which is estimated above as Eq. (18). Alternatively, the hypothesis that the central bank follows a partial adjustment Rule 1 is $\mathrm{H} 1_{P A}: \rho_{1}^{b}=0$ (with $\left.\rho_{1}^{a} \equiv \rho_{1} \neq 0\right)$. With this restriction, the estimated version of Eq. (20) matches the partial adjustment form Eq. (2). ${ }^{29}$

\footnotetext{
${ }^{28}$ Rule 1 with an AR(1) error is estimated via maximum likelihood, while rule 2 with an $\mathrm{AR}(1)$ error is estimated with an instrumental variables version of the Hildreth-Lu procedure.

${ }^{29}$ Of course, the $\hat{g}_{\pi}$ and $\hat{g}_{y}$ in Eq. (20) would equal $\left(1-\hat{\rho}_{1}\right)$ times the corresponding estimates in Eq. (2).
} 
Unfortunately, it is difficult to obtain decisive direct empirical evidence against either of these hypotheses. Over the 1987 to 1999 sample, the p-value of the serially correlated shock hypothesis $\mathrm{H} 1_{S C}$ is 0.18 , while the $\mathrm{p}$-value for the partial adjustment hypothesis $\mathrm{H} 1_{P A}$ is 0.14 . That is, over this sample, there is little evidence to reject either of these two forms. Even worse, the evidence appears quite fragile to even modest changes in the sample. For example, as shown in Table 5, in a slightly shorter sample, the serially correlated shock Rule 1 is rejected, while in a slightly longer sample, the partial adjustment Rule 1 is rejected. (The $\mathrm{p}$-value of $\mathrm{H} 1_{S C}$ is zero in the 1987-1996 sample, and the $\mathrm{p}$-value of $\mathrm{H} 1_{P A}$ is zero in the 1983-1999 sample.) Similarly fragile results are given in Table 5 for Rule 2 as well.

This difficulty in distinguishing partial adjustment from serially correlated shocks is consistent with the inventory adjustment econometrics literature cited above. The choice between these two forms of modeling dynamics depends crucially on separating the influences of contemporaneous and lagged regressors, which are especially difficult to untangle for empirical monetary policy rules for several reasons. First, the arguments of the rules-four-quarter inflation and the output gap - are highly serially correlated, so distinguishing the effect of, say, $\bar{\pi}_{t}$ from $\bar{\pi}_{t-1}$ is not easy. Second, the arguments of the rules are not exogenous (as is often assumed in the inventory adjustment literature) but depend crucially on past interest rates. Third, only short data samples of plausibly consistent rule behavior are available with a limited amount of business cycle variation in output and inflation. Fourth, there is some uncertainty about the appropriate arguments of the historical policy rule. Finally, the actual interest rates are set on the basis of real-time data on output and inflation, which also makes it difficult to determine the correct dynamics (see Rudebusch 1998, 2001, 2002, and the discussion below). Indeed, the near-observational equivalence of partial adjustment and serially correlated shocks for monetary policy rules provides a key motivation for examining the indirect term structure evidence as above.

The estimated partial adjustment policy rules failed the indirect term structure test in Section 5 by implying too much interest rate forecastability, but the serially correlated shocks in the nearobservationally-equivalent estimated rules in Eqs. (18) and (19) may also translate into interest rate forecastability. Certainly, in the general form of Eq. (20), as $\rho_{1}^{a}$ increases for fixed $\rho_{1}^{b}$, the forecastability of interest rates should increase as it did for the standard partial adjustment model. Indeed, in Figure 1, with $\rho_{1}^{b}$ equal to zero, forecastability increased with $\rho_{1}^{a} \equiv \rho_{1}$. However, in the general case, this intuition ignores the offsetting effect on forecastability of 
simultaneously increasing $\rho_{1}^{b}$. Since $\bar{\pi}_{t}$ and $y_{t}$ are persistent processes, as $\rho_{1}^{b}$ increases, the term $g_{\pi} \bar{\pi}_{t}+g_{y} y_{t}-\rho_{1}^{b}\left(g_{\pi} \bar{\pi}_{t-1}+g_{y} y_{t-1}\right)$ becomes less predictable. This effect is illustrated in Figure 2 , which examines the forecastability of interest rates (again as measured by the $R^{2}$ of the term structure regression) with the rule in Eq. (20) (in a model with $\mu_{\pi}=.3, \mu_{r}=.5$, and $\mu_{y}=0$ ). As shown by the downward-sloping thin solid line, with $\rho_{1}^{a}$ set equal to 0.7 , as $\rho_{1}^{b}$ increases from zero to 0.6 , the forecastability of $\Delta i_{t+2}$ declines. The thin dashed line gives a similar result for Rule 2. The thicker lines in Figure 2 give the effect on interest rate predictability of simultaneously increasing $\rho_{1}^{a}$ and $\rho_{1}^{b}$. In particular, the thick solid line shows the forecastability of $\Delta i_{t+2}$ for the rule with $\rho_{1}^{a}=\rho_{1}^{b} \equiv \rho_{1}^{e}$, which matches the $\operatorname{AR}(1)$ shock rule. As $\rho_{1}^{e}$, the persistence of the policy rule shocks, increases, the forecastability of interest rate changes is remarkably unaffected. The thick dashed line shows a similar result for Rule 2 .

Figure 2 gives analytical, asymptotic results, so Table 5 provides some relevant small sample evidence. Rules 1 and 2 take forms similar to the ones above, with $g_{\pi}=1.5, g_{y}=.8, \rho_{1}=\rho_{2}=0$, and an $\operatorname{AR}(1)$ shock calibrated with $\rho_{1}^{e}=\rho_{2}^{e}=0.90$ and $\sigma_{\omega}=0.4$. The resulting $R_{L}^{2}$ and $R_{U}^{2}$ pairs for the $\Delta i_{t+2}$ and $\Delta i_{t+3}$ prediction regressions, show that these rules with serially correlated shocks display little interest rate forecastability, which is consistent with the historical results. (For brevity, only the median intervals across the 18 models are provided.)

Much has been written about monetary policy "shocks," such as the $\xi_{t}$, in the literature, so it is useful to provide some economic interpretation of these persistent rule deviations. Recall the original analysis of Taylor (1993), which put forward a description of monetary policy that did not involve interest rate smoothing or partial adjustment. Taylor argued that recent historical monetary policy had followed a rule only as a guide, so deviations from the rule during various episodes were an appropriate response to special circumstances, not evidence of partial adjustment. This view is illustrated in Figure 3, which displays the historical values of the funds rate (solid line) and the fitted values (dashed line) from the estimated non-inertial Rule 1 in Eq. (18), which allows for serially correlated shocks. The associated large persistent shocks, that is, the deviations between the two lines, appear to correspond to several special episodes. ${ }^{30}$ Most notably, the deviations in 1992 and 1993 are commonly interpreted as responses to a disruption in the flow of credit. As Fed Chairman Alan Greenspan testified to Congress on June 22, 1994:

\footnotetext{
${ }^{30}$ Kozicki (1999, p. 24) also makes the point that ". . . information and events outside the scope of Taylor-type rule specifications ..." often appear to influence policy actions.
} 
"Households and businesses became much more reluctant to borrow and spend and lenders to extend credit - a phenomenon often referred to as the 'credit crunch.' In an endeavor to defuse these financial strains, we moved short-term rates lower in a long series of steps that ended in the late summer of 1992, and we held them at unusually low levels through the end of 1993-both absolutely and, importantly, relative to inflation." Thus, this episode appears better described as a persistent "credit crunch" shock than as a sluggish partial adjustment to a known desired rate. Similarly, a worldwide financial crisis appeared to play a large role in lowering rates in 1998 and 1999, and commodity price scares pushed rates up in 1988-89 and 1994-95. ${ }^{31}$

This description of credit crunches and financial crises clarifies the fact that these rule deviations are not "exogenous policy shocks," that is, actions undertaken by central bankers that are independent of the economy (and the focus of the VAR literature). Instead, these deviations are endogenous responses to a variety of influences that cannot be captured by some easily observable variable such as output or inflation. ${ }^{32}$ In terms of the Taylor rule in Eq. (1), one interpretation of the rule deviations is of fluctuations in the equilibrium real rate, $r^{*}$. For example, as suggested by Greespan's testimony, a disruption of credit supply could be treated as a temporary lowering of the equilibrium real rate, and in response, the Fed lowers the funds rate relative to readings on output and inflation. It should be clear that the modeling of these shocks to the Taylor rule as an AR(1) process, as in Eq. (18), is simply a convenient econometric approximation. ${ }^{33}$

\footnotetext{
${ }^{31}$ Federal Reserve Governor Laurence Meyer (1999, p. 7) had this explanation for the easing of policy during late 1998: "There are three developments, each of which, I believe, contributed to this decline in the funds rate relative to Taylor Rule prescription. The first event was the dramatic financial market turbulence, following the Russian default and devaluation. The decline in the federal funds rate was, in my view, appropriate to offset the sharp deterioration in financial market conditions, including wider private risk spreads, evidence of tighter underwriting and loan terms at banks, and sharply reduced liquidity in financial markets."

${ }^{32}$ Rules 1 and 2 may appear too parsimonious so that the persistent deviations reflect a serially correlated omitted variable; however, as noted above, the empirical reaction function literature, including monetary VARs, has placed the proverbial kitchen sink on the right-hand side in attempts to explain the policy rate, yet serially correlated errors remain, which are modeled through lagged interest rates and partial adjustment. Again, see Rudebusch (1998) and Goodfriend (2000).

${ }^{33}$ As an alternative, Gerlach and Schnabel (2000) include in their estimated Taylor rule for Europe a dummy variable intercept shift for a large persistent rule deviation. They find (p. 167) that a European Taylor rule fits well without partial adjustment but with “. . . dummies for the period 1992:3-1993:3 to control for policy responses to intra-European exchange market pressures in this period"
} 
A complementary rationale for the serially correlated shocks has also been discussed in the policy rules literature. Several recent papers (e.g., Smets, 1999, Rudebusch, 2001, 2002, and Orphanides, et al., 1999) have stressed that setting monetary policy according to a Taylor rule requires relying on a "real-time" estimate of the output gap. They advocate a "real-time analysis" (as defined by Diebold and Rudebusch, 1991), which uses the sequential information sets that were actually available as history unfolded. The available historical data suggest that the real-time output gap estimates, denoted $y_{t \mid t}$, are very noisy versions of the final estimates, $y_{t}$. The large and persistent revisions, $n_{t}$, can be defined by $y_{t \mid t}=y_{t}+n_{t}$. In this case, even if the central bank follows Rule 1 with no partial adjustment or error in real time,

$$
i_{t}=g_{\pi} \bar{\pi}_{t}+g_{y} y_{t \mid t}
$$

the econometrician working with the final data will estimate

$$
i_{t}=\hat{g}_{\pi} \bar{\pi}_{t}+\hat{g}_{y} y_{t}+k_{t}
$$

where the error $k_{t}=\hat{g}_{y} n_{t}$ is the highly serially correlated real-time data noise. Lansing (2000) provides a careful simulation study that demonstrates the potential effectiveness of such real-time output gap errors to account for the spurious evidence of policy inertia in exactly this fashion. ${ }^{34}$ Indeed, based on a reconstruction of real-time output gap data for the U.S., Mehra (2001) reports that the evidence for policy inertia and interest rate smoothing disappears when estimating partial adjustment rules using the real-time data. Real-time output gap revisions may not be a complete explanation because there are estimated reaction functions with significant inertia that do not include an output gap (for example, McNees, 1992, McCallum and Nelson, 1999, Fair, 2000, and the VAR interest rate equations); however, it seems likely that in general the real-time information set is an important element in accounting for spuriously inertial estimated policy rules.

\section{Conclusion}

Empirical monetary policy rules with large estimated coefficients on the lagged policy interest rate, which are very prevalent in the literature, are widely interpreted as indicating a sluggish adjustment of the policy rate to its determinants - on the order of only about 20 percent per

\footnotetext{
${ }^{34}$ Much earlier, Goodfriend (1985) also showed that measurement error in the variables determining money demand could result in spuriously significant partial adjustment lags.
} 
quarter. This partial adjustment implies predictable future changes in the policy rate over horizons of several quarters, which does not accord with the lack of information about such changes in financial markets. This paper proposes a resolution of this empirical inconsistency by providing an alternative interpretation of the large lag coefficients in the estimated policy rules. These coefficients reflect serially correlated or persistent special factors or shocks that cause the central bank to deviate from the policy rule.

This argument uses indirect term structure evidence to dismiss the interest rate smoothing interpretation of the partial adjustment rule. As noted above, it appears difficult to develop direct evidence against the partial adjustment rule (in the form of non-rejection of the $\rho=$ 0 hypothesis). In particular, the uncertainty in modeling the desired policy rate (given the endogeneity of its determinants, the real-time nature of the information set, as well as the small samples available) makes any direct evidence from estimated rules fragile. For example, the rule with partial adjustment and the rule with serially correlated shocks both appear to fit the data as empirical reaction functions. However, they have very different economic interpretations. In the former rule, persistent deviations from an output and inflation response occur because policymakers are slow to react. In the latter rule, these deviations reflect the policymaker's response to other persistent influences. The two types of rules can be distinguished, however, by their very different implications for the term structure. Only the serially correlated shocks rule is consistent with the historical evidence showing that the term structure is largely uninformative about the future course of the policy rate.

There may be other possible reconciliations of the policy rule and term structure empirical results. For example, it may be that the rational expectations hypothesis of the term structure cannot be applied and the associated term structure interpretations above are spurious. One way in which this hypothesis may fail is that expectations are not rational, but this would undermine many aspects of any explicitly forward-looking macroeconomic modeling exercise such as the one above. Or term premia for short-term interest rates may be even more volatile than assumed above; however, if rates are driven by volatile term premia, then it seems unlikely that they can communicate the subtle expectations of future monetary policy as required in the literature on optimal monetary policy inertia.

It is also possible that there is some intermediate case of partial adjustment, a $\rho_{1}$ or $\rho_{2}$ of 0.4, say, along with some serially correlated shocks, that is not strictly rejected by the term structure evidence. However, it should be noted that while real-world discussions of monetary 
policy sometimes mention the "incrementalism" and "gradualism" of smoothing the policy rate over the next several weeks, there is no acknowledgment of quarterly interest rate smoothing. ${ }^{35}$ As the New York Times (July 26, 2000) summarized of recent Congressional testimony: "Alan Greenspan, the Federal Reserve chairman, said today that the central bank's decision about whether to raise interest rates again at its meeting next month would hinge in large part on economic data released in coming weeks." That is, there was little if any pent-up pressure from the past for further adjustment.

In future research, the empirical rules given in Section 6 can be improved as further effort is made in estimating rules without the crutch of partial adjustment. Given the similar estimates above of $g_{\pi}$ and $g_{y}$ across rules, it may be that past conclusions about these coefficients, as in Clarida, Gali, and Gertler (2000), are robust to the exact formulation of serial correlation in the rule. However, the lagged policy rate, though useful in mopping up residual serial correlation, should not be given a structural partial adjustment interpretation with regard to central bank behavior. In particular, using the partial adjustment rule in a model as a representation of historical policy (as in Levin, Wieland, and Williams, 1999, and many other studies) may give misleading results, especially about the nature of optimal policy inertia.

With regard to optimality, the maintained hypothesis of economics for central banks, as for other agents in the economy, is that the non-inertial policy rule apparently used in practice is optimal, and certainly, the rule can be rationalized as such in particular models as in Table 2 . However, it should be stressed that there are many aspects of the monetary policy process still to be modeled, especially imperfect credibility and uncertainty (see Rudebusch, 2001).

Also, the absence of partial adjustment does not mean that central banks are not trying to influence long-term interest rates. However, in order to influence the long rate, central banks only must present a clear path for the policy rate that can shape expected future rates. The partial adjustment rule provides one such path, but it is not the only one. As noted by Goodfriend (1991) and Rudebusch (1995), an ex ante constant path, which is approximately what the non-inertial rules deliver, is another obvious choice.

Finally, further careful analysis of the empirical policy rule is required in modeling and identifying the shocks. Section 6 provides a simple formulation for adding shocks to a policy

\footnotetext{
${ }^{35}$ And as noted in the introduction, models of monthly interest rate smoothing imply very little if any quarterly interest rate smoothing.
} 
rule. A better specification may link persistent shocks in both the rule and the rest of the model. A bout of credit frictions or impediments may lower the equilibrium real rate and provide a persistent negative shock to the policy rule and to the output equation as well (see Rudebusch, 2001). Alternatively, an idiosyncratic inflation scare may provide a shock to the rule and to inflation expectations more broadly. 
Table 1

Model parameter values

\begin{tabular}{|c|c|}
\hline Coefficient & Value \\
\hline$\alpha_{\pi 1}$ & .67 \\
\hline$\alpha_{\pi 2}$ & -.14 \\
\hline$\alpha_{\pi 3}$ & .40 \\
\hline$\alpha_{\pi 4}$ & .07 \\
\hline$\alpha_{y}$ & .13 \\
\hline$\beta_{y 1}$ & 1.15 \\
\hline$\beta_{y 2}$ & -.27 \\
\hline$\beta_{r}$ & .09 \\
\hline$\sigma_{\varepsilon}$ & 1.012 \\
\hline$\sigma_{\eta}$ & .833 \\
\hline
\end{tabular}


Table 2

Optimal lag coefficients for policy Rules 1 and 2

\begin{tabular}{|c|c|c|c|c|c|c|}
\hline \multicolumn{3}{|c|}{ Model } & \multicolumn{2}{|c|}{ Loss: $\lambda=1 ; \nu=.5$} & \multicolumn{2}{|c|}{ Loss: $\lambda=1 ; \nu=$} \\
\hline$\mu_{r}$ & $\mu_{\pi}$ & $\mu_{y}$ & $\rho_{1}$ & $\rho_{2}$ & $\rho_{1}$ & $\rho_{2}$ \\
\hline .1 & .1 & 0 & .27 & .47 & .00 & .22 \\
\hline .1 & .3 & 0 & .25 & .47 & .00 & .25 \\
\hline .1 & .5 & 0 & .25 & .55 & .00 & .33 \\
\hline .1 & .1 & .3 & .16 & .40 & .00 & .14 \\
\hline .1 & .3 & .3 & .16 & .43 & .00 & .18 \\
\hline .1 & .5 & .3 & .18 & .53 & .00 & .27 \\
\hline .5 & .1 & 0 & .57 & .67 & .50 & .51 \\
\hline .5 & .3 & 0 & .55 & .67 & .49 & .53 \\
\hline .5 & .5 & 0 & .57 & .73 & .50 & .62 \\
\hline .5 & .1 & .3 & .56 & .69 & .50 & .56 \\
\hline .5 & .3 & .3 & .56 & .71 & .49 & .55 \\
\hline .5 & .5 & .3 & .59 & .73 & .51 & .59 \\
\hline .9 & .1 & 0 & .70 & .73 & .62 & .55 \\
\hline .9 & .3 & 0 & .72 & .73 & .65 & .58 \\
\hline .9 & .5 & 0 & .74 & .79 & .68 & .70 \\
\hline .9 & .1 & .3 & .74 & .75 & .67 & .58 \\
\hline .9 & .3 & .3 & .75 & .74 & .70 & .57 \\
\hline .9 & .5 & .3 & .77 & .77 & .75 & .64 \\
\hline
\end{tabular}

N otes: The optimal lag coefficients for Rules 1 and $2-\rho_{1}$ and $\rho_{2}$, respectively - are reported for each of eighteen parameterizations of the model, which have various $\mu_{\pi}, \mu_{y}$, and $\mu_{r}$ weights on expectational terms, and for both parameterizations of the loss function. Both loss function parameterizations have equal weight on output and inflation volatility $(\lambda=1)$ but a stronger $(\nu=.5)$ or weaker $(\nu=.1)$ interest rate smoothing motive. The associated optimal $g_{\pi}$ and $g_{y}$ are not reported. 


\section{Table 3}

Predicting $\Delta i_{t+2}$ with various models and rules

\begin{tabular}{|c|c|c|c|c|c|c|c|c|c|c|}
\hline & & & \multicolumn{4}{|c|}{ Rule 1} & \multicolumn{4}{|c|}{ Rule 2} \\
\hline \multicolumn{3}{|c|}{ Model } & \multicolumn{2}{|c|}{$\rho_{1}=0$} & \multicolumn{2}{|c|}{$\rho_{1}=.8$} & \multicolumn{2}{|c|}{$\rho_{2}=0$} & \multicolumn{2}{|c|}{$\rho_{2}=.8$} \\
\hline$\mu_{r}$ & $\mu_{\pi}$ & $\mu_{y}$ & $R_{L}^{2}$ & $R_{U}^{2}$ & $R_{L}^{2}$ & $R_{U}^{2}$ & $R_{L}^{2}$ & $R_{U}^{2}$ & $R_{L}^{2}$ & $R_{U}^{2}$ \\
\hline .1 & .1 & 0 & .02 & .22 & .12 & .55 & .00 & .13 & .18 & .59 \\
\hline .1 & .3 & 0 & .03 & .25 & .19 & .71 & .00 & .13 & .24 & .66 \\
\hline .1 & .5 & 0 & .07 & .40 & .65 & .98 & .02 & .15 & .33 & .75 \\
\hline .1 & .1 & .3 & .04 & .27 & .13 & .52 & .02 & .20 & .17 & .55 \\
\hline .1 & .3 & .3 & .04 & .28 & .19 & .65 & .03 & .20 & .20 & .59 \\
\hline .1 & .5 & .3 & .07 & .32 & .36 & .89 & .04 & .20 & .24 & .64 \\
\hline .5 & .1 & 0 & .01 & .21 & .11 & .52 & .00 & .12 & .16 & .56 \\
\hline .5 & .3 & 0 & .02 & .24 & .17 & .67 & .00 & .12 & .21 & .63 \\
\hline .5 & .5 & 0 & .07 & .37 & .42 & .90 & .01 & .13 & .29 & .71 \\
\hline .5 & .1 & .3 & .03 & .25 & .10 & .48 & .02 & .17 & .13 & .50 \\
\hline .5 & .3 & .3 & .03 & .25 & .14 & .58 & .02 & .17 & .16 & .54 \\
\hline .5 & .5 & .3 & .05 & .28 & .20 & .67 & .03 & .17 & .18 & .56 \\
\hline .9 & .1 & 0 & .01 & .21 & .10 & .50 & .00 & .11 & .14 & .53 \\
\hline .9 & .3 & 0 & .02 & .23 & .16 & .64 & .00 & .10 & .19 & .59 \\
\hline .9 & .5 & 0 & .06 & .35 & .34 & .82 & .01 & .11 & .25 & .68 \\
\hline .9 & .1 & .3 & .02 & .23 & .08 & .44 & .01 & .15 & .11 & .46 \\
\hline .9 & .3 & .3 & .02 & .23 & .11 & .50 & .01 & .15 & .12 & .48 \\
\hline .9 & .5 & .3 & .04 & .26 & .13 & .52 & .03 & .16 & .13 & .48 \\
\hline & Medi & & .03 & .25 & .15 & .61 & .01 & .15 & .18 & .57 \\
\hline
\end{tabular}

Notes: For eighteen models, non-inertial $\left(\rho_{1}=0\right)$ and inertial $\left(\rho_{1}=.8\right)$ versions of Rule 1 and non-inertial $\left(\rho_{2}=0\right)$ and inertial $\left(\rho_{2}=.8\right)$ versions of Rule 2 are considered. For each combination of model and rule, 5,000 samples of 100 observations of data are generated. A term structure regression like Eq. (16) is estimated for each sample, and the resulting distributions of $R^{2}$ values are summarized by $R_{L}^{2}$ and $R_{U}^{2}$, the 5 percent lower and upper critical values. The median values of these critical values across the eighteen models are also reported. 
Table 4

Predicting $\Delta i_{t+3}$ with various models and rules

\begin{tabular}{|c|c|c|c|c|c|c|c|c|c|c|}
\hline & & & \multicolumn{4}{|c|}{ Rule 1} & \multicolumn{4}{|c|}{ Rule 2} \\
\hline \multicolumn{3}{|c|}{ Model } & \multicolumn{2}{|c|}{$\rho_{1}=0$} & \multicolumn{2}{|c|}{$\rho_{1}=.8$} & \multicolumn{2}{|c|}{$\rho_{2}=0$} & \multicolumn{2}{|c|}{$\rho_{2}=.8$} \\
\hline$\mu_{r}$ & $\mu_{\pi}$ & $\mu_{y}$ & $R_{L}^{2}$ & $R_{U}^{2}$ & $R_{L}^{2}$ & $R_{U}^{2}$ & $R_{L}^{2}$ & $R_{U}^{2}$ & $R_{L}^{2}$ & $R_{U}^{2}$ \\
\hline .1 & .1 & 0 & .01 & .21 & .05 & .47 & .00 & .13 & .06 & .46 \\
\hline .1 & .3 & 0 & .02 & .22 & .11 & .65 & .00 & .13 & .09 & .53 \\
\hline .1 & .5 & 0 & .06 & .37 & .59 & .98 & .01 & .14 & .16 & .64 \\
\hline .1 & .1 & .3 & .02 & .24 & .06 & .45 & .01 & .17 & .06 & .42 \\
\hline .1 & .3 & .3 & .03 & .24 & .11 & .59 & .01 & .17 & .08 & .47 \\
\hline .1 & .5 & .3 & .06 & .30 & .29 & .87 & .02 & .18 & .11 & .52 \\
\hline .5 & .1 & 0 & .01 & .20 & .04 & .44 & .00 & .11 & .05 & .43 \\
\hline .5 & .3 & 0 & .01 & .22 & .10 & .61 & .00 & .11 & .07 & .50 \\
\hline .5 & .5 & 0 & .06 & .35 & .34 & .88 & .01 & .12 & .13 & .59 \\
\hline .5 & .1 & .3 & .02 & .22 & .04 & .40 & .00 & .15 & .04 & .37 \\
\hline .5 & .3 & .3 & .02 & .23 & .08 & .50 & .01 & .15 & .05 & .41 \\
\hline .5 & .5 & .3 & .05 & .27 & .13 & .62 & .01 & .15 & .07 & .43 \\
\hline .9 & .1 & 0 & .01 & .20 & .03 & .41 & .00 & .10 & .04 & .39 \\
\hline .9 & .3 & 0 & .01 & .22 & .09 & .57 & .00 & .10 & .06 & .46 \\
\hline .9 & .5 & 0 & .05 & .33 & .25 & .78 & .01 & .11 & .10 & .54 \\
\hline .9 & .1 & .3 & .01 & .21 & .03 & .35 & .00 & .12 & .02 & .32 \\
\hline .9 & .3 & .3 & .02 & .22 & .05 & .42 & .00 & .12 & .03 & .34 \\
\hline .9 & .5 & .3 & .04 & .26 & .07 & .45 & .01 & .13 & .04 & .35 \\
\hline & Medi & & .02 & .23 & .08 & .54 & .01 & .13 & .06 & .44 \\
\hline
\end{tabular}

Notes: For eighteen models, non-inertial $\left(\rho_{1}=0\right)$ and inertial $\left(\rho_{1}=.8\right)$ versions of Rule 1 and non-inertial $\left(\rho_{2}=0\right)$ and inertial $\left(\rho_{2}=.8\right)$ versions of Rule 2 are considered. For each combination of model and rule, 5,000 samples of 100 observations of data are generated. A term structure regression like Eq. (17) is estimated for each sample, and the resulting distributions of $R^{2}$ values are summarized by $R_{L}^{2}$ and $R_{U}^{2}$, the 5 percent lower and upper critical values. The median values of these critical values across the eighteen models are also reported. 
Table 5

Partial adjustment and serially correlated shock rule p-values

\begin{tabular}{|c|c|c|c|c|c|}
\hline \multicolumn{2}{|c|}{ Sample } & \multicolumn{2}{|c|}{ Rule 1} & \multicolumn{2}{|c|}{ Rule 2} \\
\hline Start date & End date & $\mathrm{H} 1_{P A}$ & $\mathrm{H} 1_{S C}$ & $\mathrm{H} 2_{P A}$ & $\mathrm{H} 2_{S C}$ \\
\hline 1987:4 & 1999:4 & .18 & .14 & .02 & .18 \\
\hline 1987:4 & 1996:4 & .27 & .00 & .56 & .11 \\
\hline 1983:4 & 1999:4 & .00 & .06 & .00 & .26 \\
\hline
\end{tabular}

Note: The table entries are $\mathrm{p}$-values of the partial adjustment (PA) or serially correlated shocks (SC) restricted versions of Rules 1 and 2.

Table 6

\section{Serially correlated shocks and interest rate forecastability}

\begin{tabular}{|c|c|c|c|c|}
\hline \multirow{2}{*}{$\begin{array}{c}\text { AR(1) shock } \\
\text { policy rule }\end{array}$} & \multicolumn{2}{|c|}{$\Delta i_{t+2}$ forecastability } & \multicolumn{2}{|c|}{$\Delta i_{t+3}$ forecastability } \\
\hline & $R_{L}^{2}$ & $R_{U}^{2}$ & $R_{L}^{2}$ & $R_{U}^{2}$ \\
\hline Rule $1\left(\rho_{1}^{e}=.90\right)$ & .05 & .31 & .04 & .28 \\
\hline Rule $2\left(\rho_{2}^{e}=.90\right)$ & .02 & .16 & .01 & .14 \\
\hline
\end{tabular}

N otes: For eighteen models, a serially correlated shocks version of Rule 1 and of Rule 2 is considered (with $\rho_{1}^{e}=\rho_{2}^{e}=.90$ ). For each combination of model and rule, 5,000 samples of 100 observations of data are generated. Term structure regressions like Eqs. (16) and (17) are estimated for each sample, and the resulting distributions of $R^{2}$ values are summarized by $R_{L}^{2}$ and $R_{U}^{2}$, the 5 percent lower and upper critical values. Only the median values of these critical values across the eighteen models are reported. 


\section{References}

[1] Amato, Jeffery, and Thomas Laubach, 1999, The Value of Interest Rate Smoothing: How the Private Sector Helps the Federal Reserve, Economic Review, Federal Reserve Bank of Kansas, Third Quarter, 47-64.

[2] Anderson, Gary S., and George Moore, 1985, A Linear Algebraic Procedure for Solving Linear Perfect Foresight Models, Economics Letters 17, 247-52.

[3] Balduzzi, Pierluigi, Giuseppe Bertola, and Silverio Foresi, 1997, A Model of Target Changes and the Term Structure of Interest Rates, Journal of Monetary Economics 39, 223-249.

[4] Blinder, Alan S., 1986, More on the Speed of Adjustment in Inventory Models, Journal of Money, Credit and Banking 18, 355-365.

[5] Clarida, Richard, Jordi Gali, and Mark Gertler, 1998, Monetary Policy Rules in Practice: Some International Evidence, European Economic Review 42, 1033-1067.

[6] Clarida, Richard, Jordi Gali, and Mark Gertler, 1999, The Science of Monetary Policy: A New Keynesian Perspective, Journal of Economic Literature 37, 1661-1707.

[7] Clarida, Richard, Jordi Gali, and Mark Gertler, 2000, Monetary Policy Rules and Macroeconomic Stability: Evidence and Some Theory, Quarterly Journal of Economics 115, 147-180.

[8] Cook, Timothy and Thomas Hahn, 1990, Interest Rate Expectations and the Slope of the Money Market Yield Curve, Economic Review, Federal Reserve Bank of Richmond, 3-15.

[9] Cukierman, Alex, 1996, Why Does the Fed Smooth Interest Rates? in: M. Belongnia, ed., Monetary Policy on the 75th Anniversary of the Federal Reserve System (Kluwer Academic Publishers, Boston) 111-147.

[10] Diebold, Francis, and Lutz Kilian, 2001, Measuring Predictability: Theory and Macroeconomic Applications, forthcoming in the Journal of Applied Econometrics.

[11] Diebold, Francis X., and Glenn D. Rudebusch, 1991, Forecasting Output With the Composite Leading Index: A Real-Time Analysis, Journal of the American Statistical Association $86,603-10$. 
[12] Dotsey, Michael, and Christopher Otrok, 1995, The Rational Expectations Hypothesis of the Term Structure, Monetary Policy and Time-Varying Term Premia, Economic Quarterly, Federal Reserve Bank of Richmond, 65-81.

[13] Eijffinger, Sylvester, Eric Schaling, and Willem Verhagen, 1999, A Theory of Interest Rate Stepping: Inflation Targeting in a Dynamic Menu Cost Model, manuscript, Tilburg University.

[14] Estrella, Arturo, and Jeffrey C. Fuhrer, 1998, Dynamic Inconsistencies: Counterfactual Implications of a Class of Rational Expectations Models, Working Paper No. 98-5, Federal Reserve Bank of Boston.

[15] Fair, Ray, 2000, Estimated, Calibrated and Optimal Interest Rate Rules, manuscript, Yale University.

[16] Fuhrer, Jeffrey C., 1996, Monetary Policy Shifts and Long-Term Interest Rates, The Quarterly Journal of Economics, November, 1183-1209.

[17] Fuhrer, Jeffrey C., 1997, The (Un)Importance of Forward-Looking Behavior in Price Specifications, Journal of Money, Credit, and Banking 29, 338-350.

[18] Fuhrer, Jeffrey C., 2000, Habit Formation in Consumption and Its Implications for Monetary-Policy Models, American Economic Review 90, 367-90.

[19] Fuhrer, Jeffery C., and George R. Moore, 1995, Monetary Policy Trade-Offs and the Correlation Between Nominal Interest Rates and Real Output, American Economic Review 85, 219-239.

[20] Gerlach, Stefan, and Gert Schnabel, 2000, The Taylor Rule and Interest Rates in the EMU Area, Economics Letters 67, 165-171.

[21] Goodfriend, Marvin, 1985, Reinterpreting Money Demand Regressions, Carnegie-Rochester Series on Public Policy 22, 207-242.

[22] Goodfriend, Marvin, 1991, Interest Rates and the Conduct of Monetary Policy, CarnegieRochester Series on Public Policy 34, 7-30.

[23] Goodfriend, Marvin, 2000, Discussion, in: K. Clinton and W. Engert, eds., Money, Monetary Policy, and Transmission Mechanisms (Bank of Canada) 413-421. 
[24] Goodfriend, Marvin, and Robert G. King, 1997, The New Neoclassical Synthesis and the Role of Monetary Policy, in NBER Macroeconomics Annual, 231-283.

[25] Goodhart, Charles, 1997, Why Do the Monetary Authorities Smooth Interest Rates? in: S. Collignon, ed., European Monetary Policy (Pinter, Washington, DC) 119-178.

[26] Goodhart, Charles, 1999, Central Bankers and Uncertainty, Bank of England Quarterly Bulletin 39, 102-115.

[27] Griliches, Zvi, 1967, Distributed Lags: A Survey, Econometrica 35, 16-49.

[28] Hall, Alastair, and Robert J. Rosanna, 1991, Estimating the Speed of Adjustment in Partial Adjustment Models, Journal of Business and Economic Statistics 9, 441-53.

[29] Hendry, David, and Grayham Mizon, 1978, Serial Correlation as a Convenient Simplification, Not a Nuisance: A Comment on a Study of the Demand for Money by the Bank of England, Economic Journal 88, 549-563.

[30] Jegadeesh, Narasimhan, and George G. Pennacchi, 1996, The Behavior of Interest Rates Implied by the Term Structure of Eurodollar Futures, Journal of Money, Credit and Banking $28,420-446$.

[31] Judd, John, and Glenn Rudebusch, 1998, Taylor's Rule and the Fed: 1970-1997, Economic Review, Federal Reserve Bank of San Francisco, no. 3, 3-16.

[32] Kozicki, Sharon, 1999, How Useful Are Taylor Rules for Monetary Policy?, Economic Review, Federal Reserve Bank of Kansas City, Second Quarter, 5-33.

[33] Kuttner, Kenneth, 2001, Monetary Policy Surprises and Interest Rates: Evidence from the Fed Funds Futures Market, Journal of Monetary Economics 47, 523-544.

[34] Lange, Joe, Brian Sack, and William Whitesell, 2001, Anticipations of monetary policy in financial markets, FEDS Working paper 2001-24, Federal Reserve Board.

[35] Lansing, Kevin, 2000, Learning About a Shift in Trend Output: Implications for Monetary Policy and Inflation, manuscript, Federal Reserve Bank of San Francisco.

[36] Levin, Andrew, Volker Wieland, and John C. Williams, 1999, Robustness of Simple Monetary Policy Rules under Model Uncertainty, in: John B. Taylor, ed., Monetary Policy Rules (Chicago University Press, Chicago) 263-299. 
[37] Lowe, Philip, and Lucy Ellis, 1997, The Smoothing of Official Interest Rates, in: Monetary Policy and Inflation Targeting: Proceedings of a Conference (Reserve Bank of Australia) 286-312.

[38] Mankiw, N. Gregory, and Jeffrey A. Miron, 1986, The Changing Behavior of the Term Structure of Interest Rates, Quarterly Journal of Economics 101, 211-28.

[39] McCallum, Bennett T., and Edward Nelson, 1999, Nominal Income Targeting in an OpenEconomy Optimizing Model, Journal of Monetary Economics 43, 553-578.

[40] McManus, Douglas, A., John C. Nankervis, and N.E. Savin, 1994, Multiple Optima and Asymptotic Approximations in the Partial Adjustment Model, Journal of Econometrics 62, 91-128.

[41] McNees, Stephen K., 1992, A Forward-Looking Monetary Policy Reaction Function: Continuity and Change, New England Economic Review, November/December, 3-14.

[42] Mehra, Yash, 2001, The Taylor principle, interest rate smoothing and Fed policy in the 1970s and 1980s, manuscript, Federal Reserve Bank of Richmond.

[43] Meyer, Laurence, 1999, The Global Economic Outlook and Challenges Facing Monetary Policy around the World, Remarks at the Annual Dinner of the Society of Business Economists, February 25, available at http://www.federalreserve.gov/boarddocs/speeches.

[44] Mishkin, Frederic S., 1988, The Information in the Term Structure: Some Further Results, Journal of Applied Econometrics 3, 307-314.

[45] Modigliani, Franco, and Robert Schiller, 1973, Inflation, Rational Expectations and the Term Structure of Interest Rates, Economica 40, 12-43.

[46] Nelson, Edward, 2000, UK Monetary Policy 1972-1997: A Guide Using Taylor Rules, Bank of England Working paper 120.

[47] Orphanides, Athanasios, Richard Porter, David Reifschneider, Robert Tetlow, and Frederico Finan, 1999, Errors in the Measurement of the Output Gap and the Design of Monetary Policy, Journal of Economics and Business 52, 117-42.

[48] Peersman, Gert, and Frank Smets, 1999, The Taylor Rule: A Useful Monetary Policy Benchmark for the Euro Area? International Finance 2, 85-116. 
[49] Roberts, John M., 1995, New Keynesian Economics and the Phillips Curve, Journal of Money and Banking 27, 975-984.

[50] Rotemberg, Julio, and Michael Woodford, 1999, Interest Rate Rules in an Estimated Sticky Price Model, in Monetary Policy Rules, in: John B. Taylor, ed., Monetary Policy Rules (Chicago University Press: Chicago) 57-119.

[51] Rudebusch, Glenn D., 1995, Federal Reserve Interest Rate Targeting, Rational Expectations, and the Term Structure, Journal of Monetary Economics 35, 245-274.

[52] Rudebusch, Glenn D., 1998, Do Measures of Monetary Policy in a VAR Make Sense? International Economic Review 39, 907-931.

[53] Rudebusch, Glenn D., 2001, Is the Fed Too Timid? Monetary Policy in an Uncertain World, Review of Economics and Statistics 83, 203-217.

[54] Rudebusch, Glenn D., 2002, Assessing Nominal Income Rules for Monetary Policy with Model and Data Uncertainty, forthcoming in the Economic Journal.

[55] Rudebusch, Glenn D., and Lars E.O. Svensson, 1999, Policy Rules for Inflation Targeting,in Monetary Policy Rules, in: John B. Taylor, ed., Monetary Policy Rules (Chicago University Press, Chicago) 203-246.

[56] Sack, Brian, 1998, Uncertainty, Learning and Gradual Monetary Policy, FEDS working paper 34, Federal Reserve Board.

[57] Sack, Brian, 2000, Does the Fed Act Gradually? A VAR Analysis, Journal of Monetary Economics 46, 229-256.

[58] Sack, Brian, and Volker Wieland, 2000, Interest Rate Smoothing and Optimal Monetary Policy: A Review of Recent Empirical Evidence, Journal of Economics and Business 52, 205-228.

[59] Smets, Frank, 1999, Output Gap Uncertainty: Does It Matter for the Taylor Rule? in: Benjamin Hunt and Adrian Orr, eds., Monetary Policy Under Uncertainty, (Reserve Bank of New Zealand) 10-29.

[60] Söderström, Ulf, 2000, Should Central Banks Be More Aggressive? manuscript, Central Bank of Sweden. 
[61] Svensson, Lars E.O., 1999a, Inflation Targeting: Some Extensions, Scandinavian Journal of Economics 101, 337-361.

[62] Svensson, Lars E.O., 1999b, Inflation Targeting as a Monetary Policy Rule, Journal of Monetary Economics 43, 607-654.

[63] Taylor, John B., 1993, Discretion versus Policy Rules in Practice, Carnegie-Rochester Conference Series on Public Policy 39, 195-214.

[64] Walsh, Carl E., 1998, Monetary Theory and Policy (MIT Press, Cambridge MA).

[65] Woodford, Michael, 1996, Control of the Public Debt: A Requirement for Price Stability? NBER Working Paper No. 5984.

[66] Woodford, Michael, 1999, Optimal Monetary Policy Inertia, The Manchester School Supplement, 1-35. 
Fig. 1. Interest rate forecastability and policy inertia

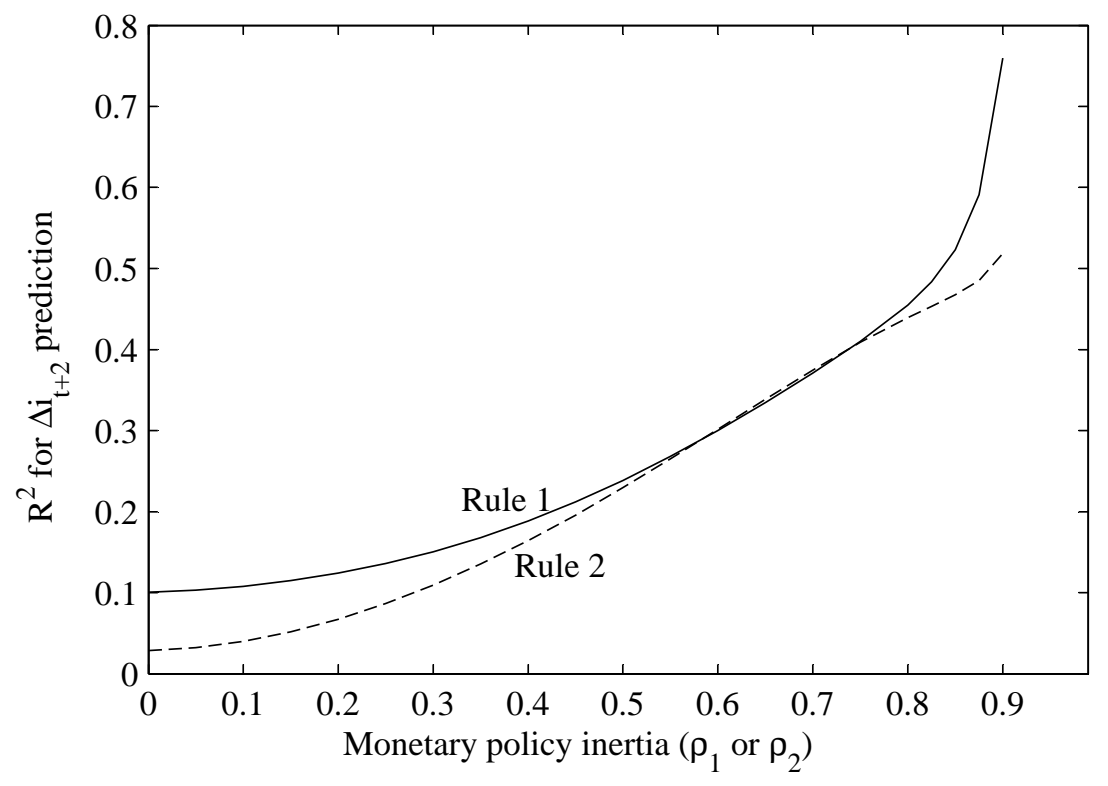


Fig. 2. Interest rate forecastability and policy shock persistence

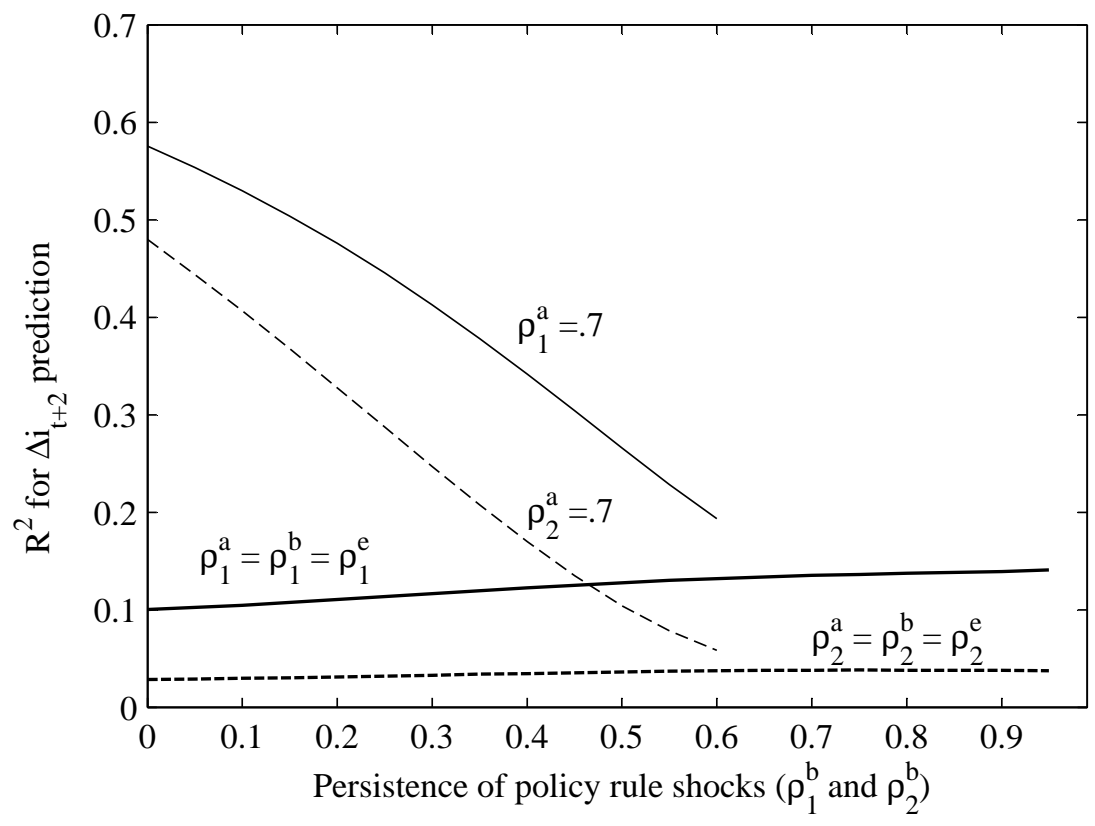


Fig. 3. Actual funds rate and an estimated non-intertial rule

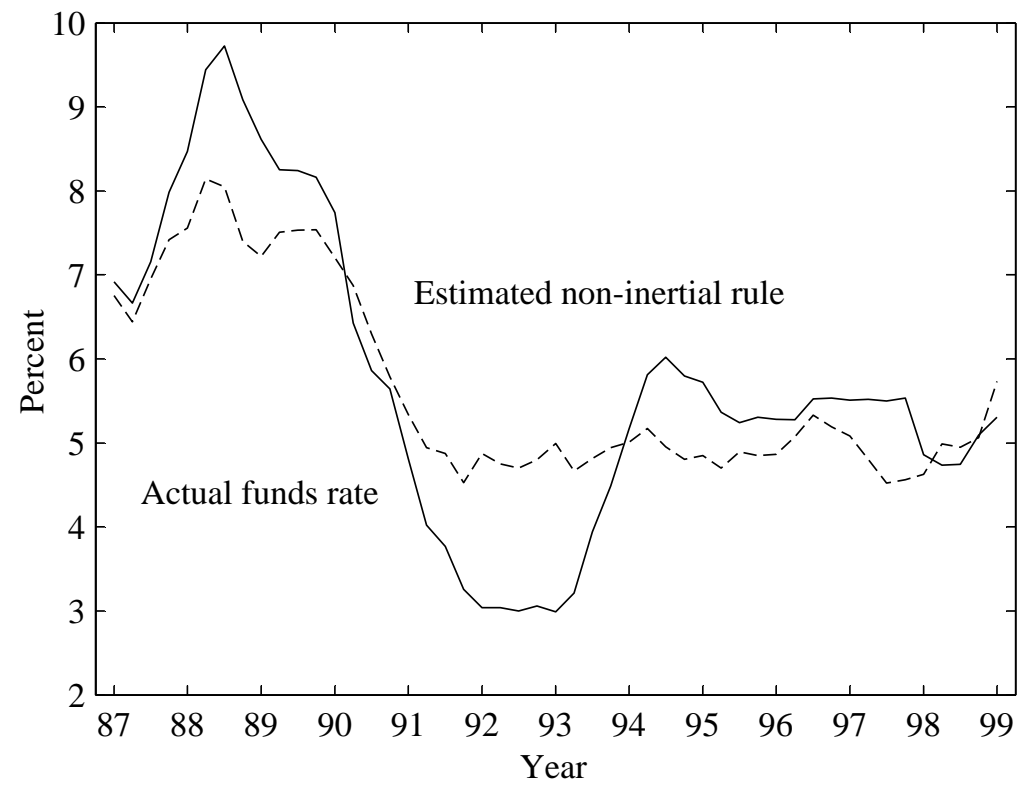

